\title{
Early fractional carbon dioxide laser intervention for postsurgical scars in skin of color
}

This article was published in the following Dove Press journal:

Clinical, Cosmetic and Investigational Dermatology

\author{
Shady M Ibrahim' \\ Wael M Saudi² \\ Mohamed F Abozeid ${ }^{3}$ \\ Mohamed L Elsaie ${ }^{4}$ \\ 'Department of Dermatology, Al \\ Azhar University, Cairo, Egypt; \\ ${ }^{2}$ Department of Dermatology, Misr \\ University for Science \& Technology, \\ 6th of October City, Egypt; \\ ${ }^{3}$ Department of Plastic surgery, Cairo \\ University, Giza, Egypt; ${ }^{4}$ Department \\ of Dermatology, National Research \\ Centre, Cairo, Egypt
}

Background: Fractional $\mathrm{CO}_{2}$ laser is one of the most effective treatment options used to resurface scars.

Objective: To evaluate the efficacy and safety of early treatment of postsurgical scar by fractional ablative $\mathrm{CO}_{2}$ laser.

Methods: A total of 27 Egyptian patients with recent postoperative scars were enrolled in this study. Three sessions of fractional $\mathrm{CO}_{2}$ laser with a 1-month interval were started 4 weeks after surgery. Vancouver Scar Scale (VSS) was used as an assessment tool at 1 and 3 months after the final treatment. Patients reported their satisfaction using a subjective 4-point scale.

Results: Results demonstrated a statistically significant overall average improvement of the VSS $(5.33 \pm 1.33)$ before compared with $(2.55 \pm 1.06) 3$ months after the last laser treatment $(P \leq 0.001)$. Among the individual parameters in the VSS, the most significant improvements were found in pigmentation, height, and pliability. Patient's subjective satisfaction scores showed a significant greater degree of satisfaction after laser treatment.

Conclusion: Fractional ablative $\mathrm{CO}_{2}$ laser is an effective and safe treatment modality for surgical scars in the early postsurgical period.

Keywords: scar, fractional, $\mathrm{CO}_{2}$ laser

\section{Introduction}

Wound healing is a complicated process, consisting of overlapping phases. These phases are hemostasis, inflammation, granulation, and remodeling. ${ }^{1}$ Any alteration in the process would lead to a variety of sequelae, including chronic wound healing and scars. ${ }^{2}$ Scars arise from either excessive or insufficient new collagen generation during the wound healing process and may appear as hypertrophic scars and atrophic scars. ${ }^{3}$

Scars affect $\sim 4.5 \%-16 \%$ of the general population and, depending on the degree of disfigurement, can have a profound impact on the psyche of the patient such as low self-esteem and feelings of psychosocial isolation. ${ }^{4}$

Surgical scars take $\sim 1$ year to fully mature, although it is well recognized that scars continue to improve in appearance after 1 year. Surgical scar revision $\sim 3$ months after surgery may be considered, but laser therapy can be considered as early as a few weeks after surgery. ${ }^{5}$

Fractional photothermolysis is a laser technology that creates thousands of microscopic columns of thermal damage (referred to as microthermal zones [MTZs]) in the epidermis and dermis surrounded by islands of normal tissue, hence results in shorter recovery time and fewer adverse effects than traditional ablative laser resurfacing. ${ }^{6}$

In recent years, early intervention with laser devices has been suggested as a novel modality to improve scar quality. Some lasers are effective not only as a treatment for
Correspondence: Mohamed L Elsaie Department of Dermatology, National Research Centre, El Buhouth St, Dokki, Cairo 12622, Egypt Email Egydoc77@yahoo.com 
scars but also in the prevention of hypertrophic scars. ${ }^{7}$ Several studies have evaluated the efficacy of nonablative fractional erbium glass, pulsed dye laser (PDL), and potassium titanyl phosphate to improve early postoperative and post-traumatic scars and a few other studies have been evaluated on the efficacy of fractional laser treatment of postoperative scars during the early post-traumatic period. ${ }^{8-11}$

Therefore, in this study, we aimed to evaluate the efficacy and safety of early treatment of postsurgical scar by fractional ablative carbon dioxide.

\section{Patients and methods}

A total of 27 Egyptian participants (15 females, 12 males; Fitzpatrick skin types III-V) aged 15-47 years, who had recent postsurgical scars (4-6 weeks after operation), were included in the study. Candidates with active infections, history of keloid, recent isotretinoin intake, smoking, and pregnancy were excluded. The study was initially approved by the ethical committee of Al-Azhar University. Written informed consent was obtained from all participants before enrollment. Parent or legal guardian of any patient under the age of 18 years signed the informed consent.

\section{Treatment protocol}

For early intervention of the postoperative scar, three sessions of fractional $\mathrm{CO}_{2} 10,600 \mathrm{~nm}$ laser (Smartxide square, Deka, Florence, Italy) with 1-month interval were started after 4-6 weeks of surgery. The treatment areas were cleansed by using a mild cleanser. A topical anesthetic cream (eutectic mixture of $2.5 \%$ lidocaine hydrochloride and $2.5 \%$ prilocaine; eutectic mixture of local anesthetics; AstraZeneca AB, Sodertalje, Sweden) was applied. After an hour of application, the anesthetic cream was gently removed to obtain a completely dry skin surface. Scarring sites were treated with fractional $\mathrm{CO}_{2}$ using a power of 10-15 W according to the skin type, dwell time of $500 \mu \mathrm{s}$, stack 2 , and $700 \mu \mathrm{m}$ spacing. The application of a sunscreen was continued. Topical antibiotic cream was applied twice per day for 3 days following the session. Patients were instructed to use a full-spectrum sunscreen regularly.

\section{Assessment}

Photographic documentation using identical camera settings, lighting, and patient positioning (CyberShot digital, DSCH50, Sony, Tokyo, Japan) were obtained at baseline, before each treatment session, and 3 months after the final treatment session.

Vancouver Scar Scale (VSS) was used by two blinded dermatologists to assess the scars at baseline and 3 months after the final treatment. The VSS includes assessment of pigmentation, height, pliability, and vascularity of the scar. Each of the four parameters was assigned numbers according to the previously mentioned characteristics. Scores from all parameters were added together to attain a final VSS score. Patients reported their satisfaction with the treatment outcomes using a subjective 4-point scale. Patients were also questioned about the side effects of the treatment, especially bleeding, oozing, posttreatment dyschromia, crusting, and erythema at each session.

\section{Statistical analysis}

SPSS software version 18 was used. In comparison to the different sessions for each participant, we estimated a $P$-value at most <0.05; consequently, we confirmed the significant difference of statistical analysis in this clinical trial.

\section{Results}

The present study was designed to evaluate safety and efficacy of early fractional $\mathrm{CO}_{2}$ laser treatment of postsurgical scar using VSS assessment. The age of the patients ranged from 15 to 47 years. Fifteen patients (44.44\%) were females and 12 patients (45\%) were males. Eleven patients $(40.74 \%)$ had skin type III, 13 patients (48.14\%) had skin type IV, and 3 patients had skin type $V(11.11 \%)$. Three patients had postrhinoplasty scar, two patients had postblepharoplasty scar, eight patients had postsurgical scar due to trauma on the face, four patients had postabdominoplasty scar, three patients had post-thigh lift scar, three patients had postsurgical scar due to trauma on the arm, two patients had postsurgical scar on the neck, one patient had postsurgical scar on the back, and one patient had postcaesarian section scar. Meanwhile, the age of the scars ranged from 2 to 6 weeks with a mean of 4.3 weeks.

The results demonstrated a statistically significant overall average improvement of the VSS (5.33 \pm 1.33$)$ before compared with $(2.55 \pm 1.06) 3$ months after the last laser treatment $(P \leq 0.001)$ (Figure 1). Among the individual parameters in

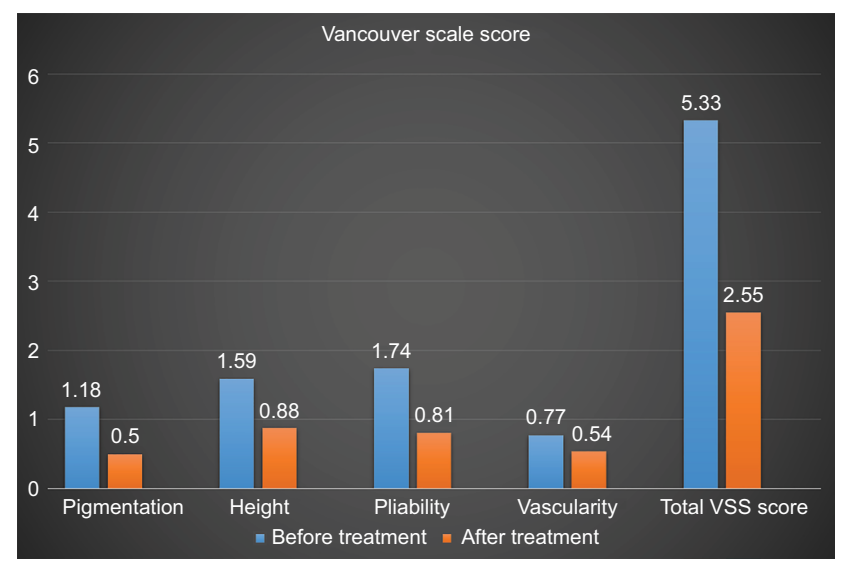

Figure I Vancouver Scale Score (VSS) (total and parameters) before and 3 months after laser treatment. 
A

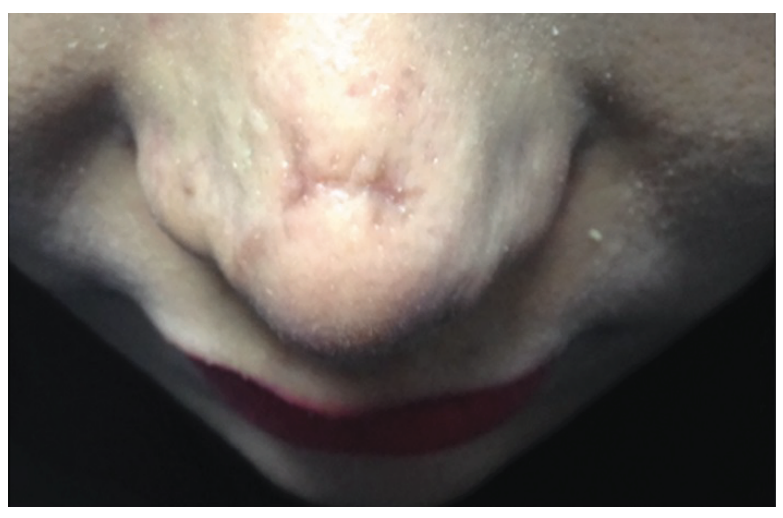

C

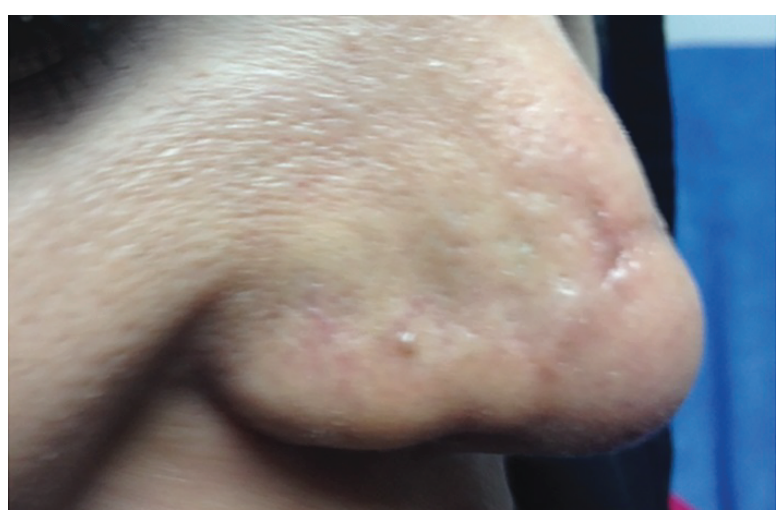

E

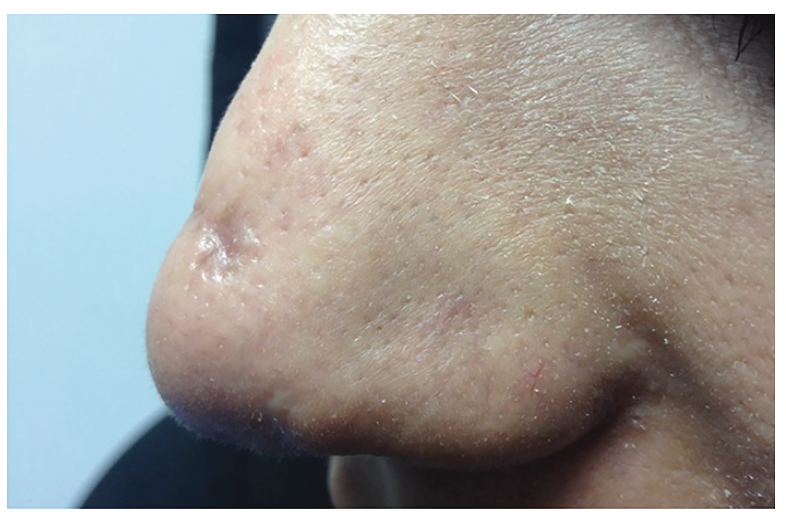

B

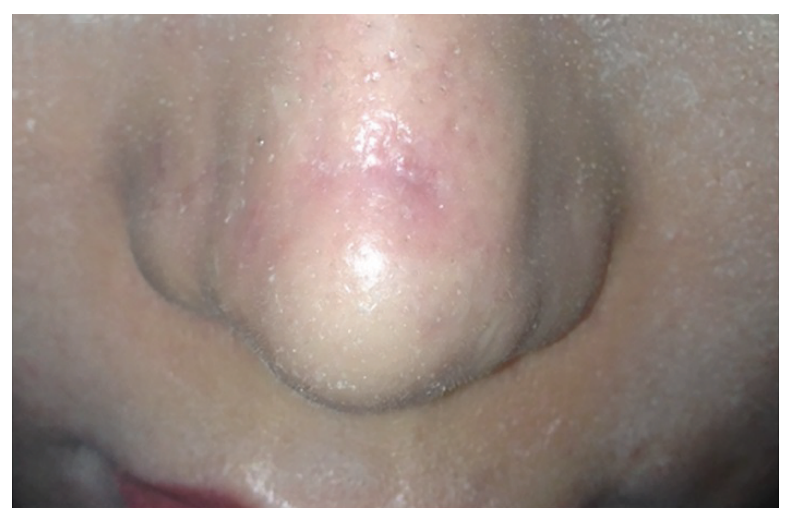

D

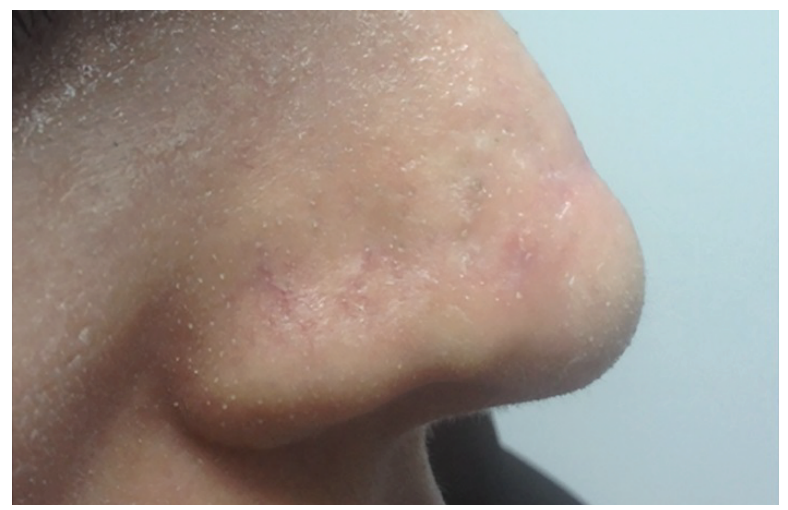

$\mathbf{F}$

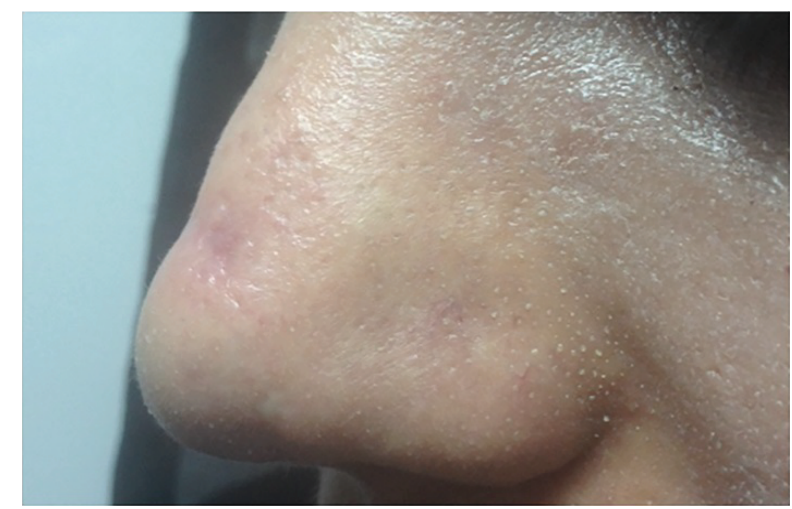

Figure 2 A 29-year-old female patient with recent postsurgical scar (rhinoplasty), before laser treatment (A, C, E) and 3 months after laser treatment (B, D, F).

the VSS, the most significant improvements were found in pigmentation, height, and pliability (Figures 2 and 3).

Patient's subjective satisfaction scores showed a greater degree of satisfaction after laser treatment, wherein six patients were very satisfied $(22.2 \%)$, eight were satisfied (29.6\%), seven were slightly satisfied (25.9\%), and six were unsatisfied $(22.2 \%)$ following three sessions of fractional $\mathrm{CO}_{2}$ laser (Figure 4). No side effects of the laser treatment were noted except one patient who showed postinflammatory hyperpigmentation.

\section{Discussion}

Conventional laser resurfacing and mechanical dermabrasion can potentially destabilize a healing tissue bed or disrupt the protective epidermal barrier prior to the incision seal. Nonablative, pulsed, or fractionated lasers place minimal 


\section{A}

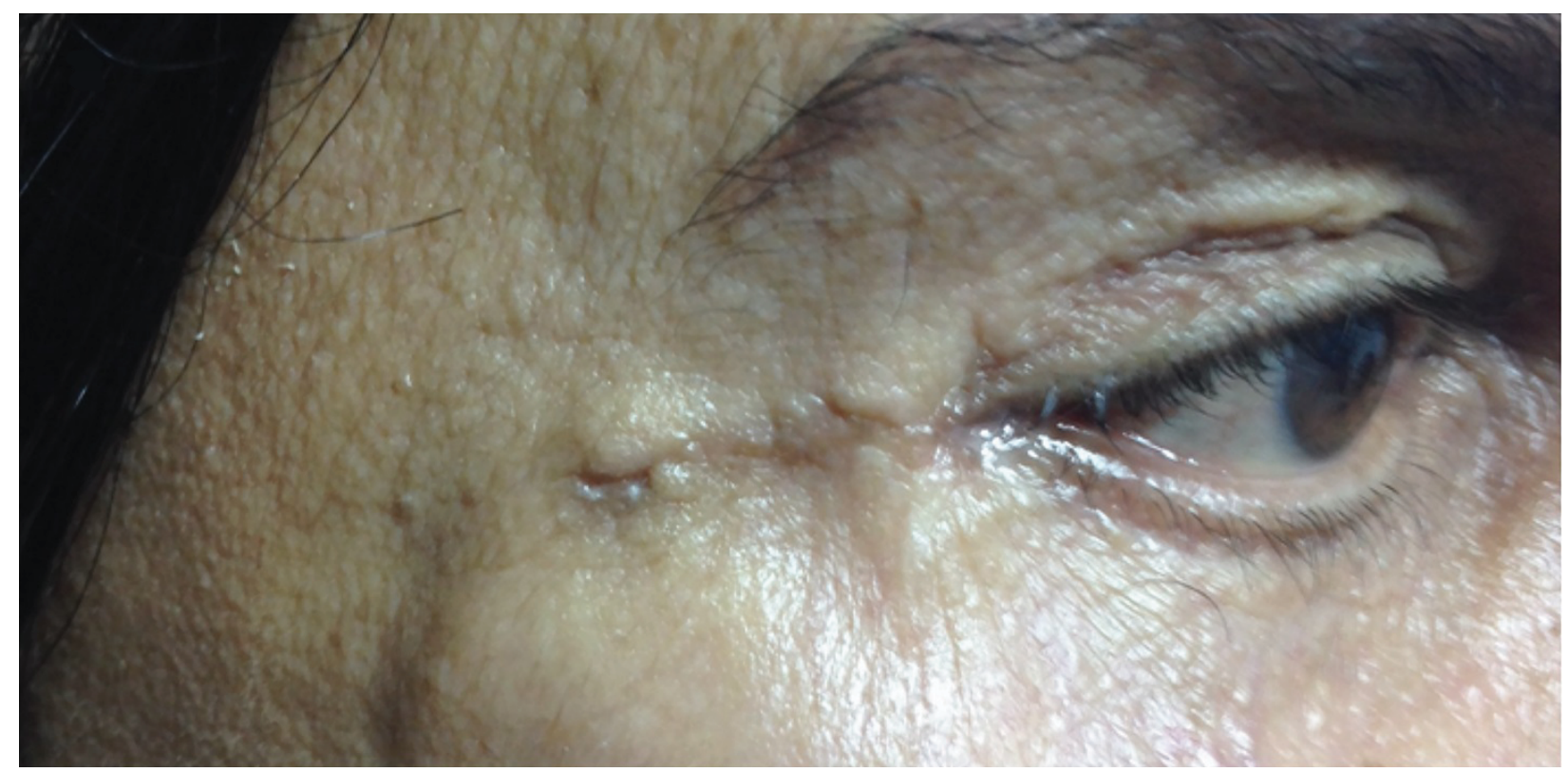

B

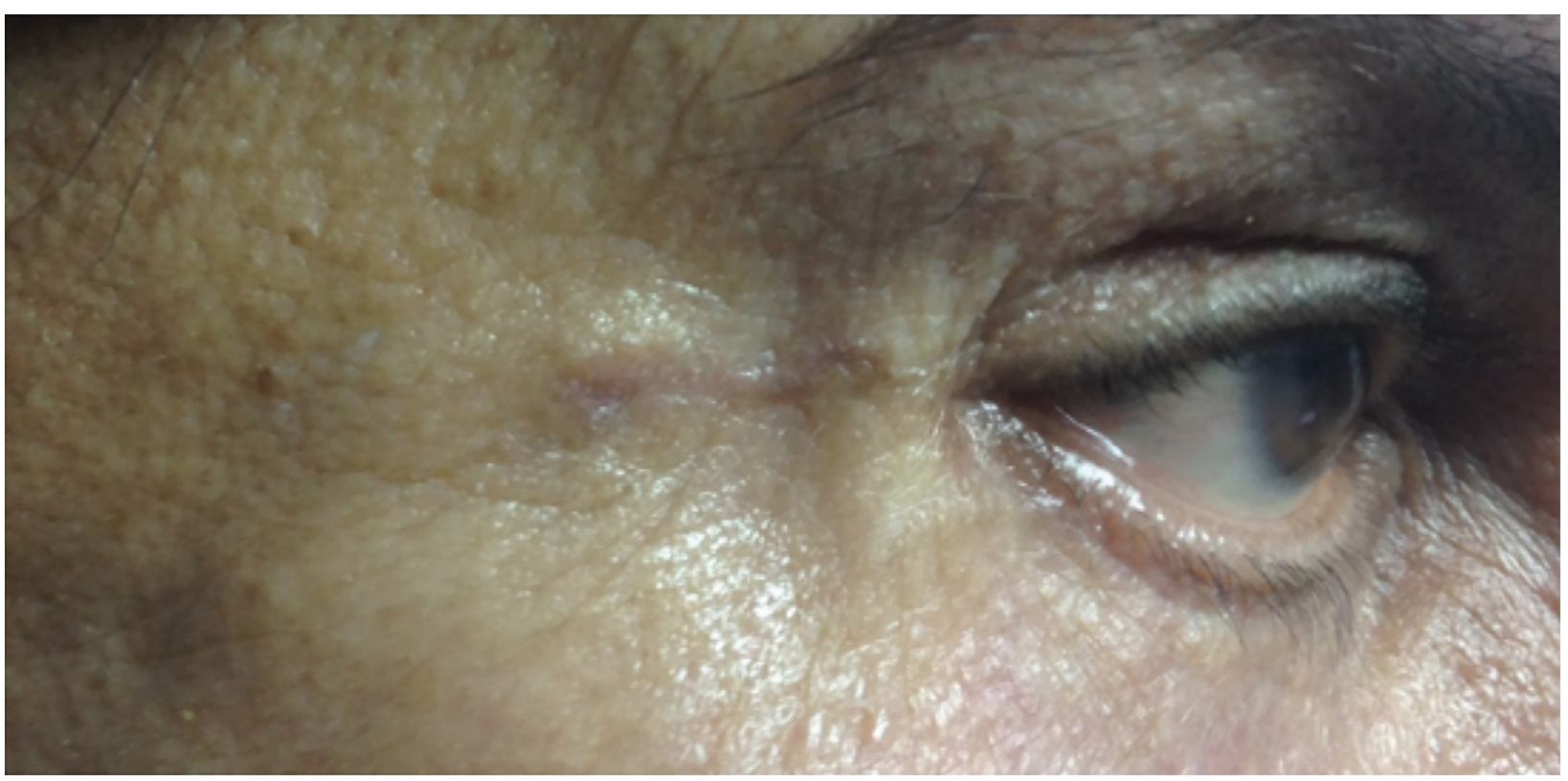

Figure 3 A 47-year-old female patient with recent postsurgical scar (blepharoplasty), before (A) and 3 months after laser treatment (B).

mechanical stress on the tissues making an option for earlier treatments. ${ }^{12}$

Early laser intervention for treatment of scars has always yielded better results. The optimal time for laser treatment was during the premature phase of scar formation at a few weeks postsurgery. ${ }^{12,13}$

This current study aimed to evaluate the possibility of early intervention of fractional $\mathrm{CO}_{2}$ laser for improving the appearance of postsurgical scars. Assessment of the erythema, height, pliability, and pigmentation was done using the VSS, which was originally designed to assess subjective parameters in an objective way. Regarding total VSS, there was a significant improvement in VSS for postsurgical scars, 3 months after last session by fractional $\mathrm{CO}_{2}$ laser. The improvement was significant in all parameters of VSS score, with higher significance in terms of height, pigmentation, and 


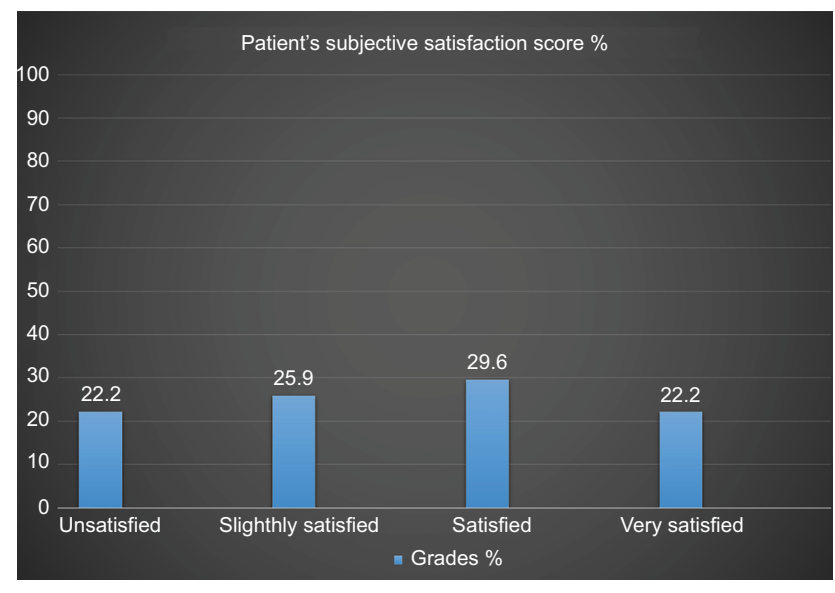

Figure 4 Patient's satisfaction score before and 3 months after laser treatment.

pliability, while less significant in terms of vascularity. In the current study, there is a significant improvement regarding patients' satisfaction grades.

Several reports have addressed the utility of PDL, nonablative fractional lasers (NAFLs), or ablative fractional lasers (AFLs) for scar prevention. One article mentioned the superiority of 1,550-nm NAFL compared with PDL on postoperative scars, and others reported the clinical effect of the PDL followed by AFL on surgical scars..$^{9,14,15}$

The effect of PDL and fractional Er:YAG laser for scars was demonstrated, especially in term of pliability, as a combined approach on post-thyroidectomy scar on the day of suture removal. ${ }^{16}$ Another study has compared the effect of $\mathrm{PDL}$ and fractional $\mathrm{CO}_{2}$ laser and revealed that both PDL and AFL produced statistically significant improvements. However, comparatively, there was no statistical difference between them. In each variable, AFL was more effective than PDL in the improvement of pliability and thickness. In contrast, PDL was superior to AFL in the improvement of vascularity and pigmentation. ${ }^{17}$

Fractional photothermolysis, first introduced by Manstein et al in $2004,{ }^{18}$ is the latest in the available phototherapeutics for scars. Fractionation refers to a technology in which thousands of laser MTZs are directed at the skin surface while sparing islands of healthy skin around it, so bulk heating and confluent epidermal damage is avoided, thereby reducing the risk of irreversible nonspecific thermal injury to the dermis, which may worsen scarring. Mechanism of action is through initial induction of proinflammatory cytokines and growth factors followed by dermal collagen remodeling. ${ }^{19}$ In another study, AFL showed better results in the overall appearance and the visibility of the incision line of fresh surgical scars than NAFL. ${ }^{20}$

In another study on 16 postoperative scars of 15 patients, a greater decrease in VSS score was noted in half of the treated scars after two sessions of fractional $\mathrm{CO}_{2}$ laser, especially in terms of texture and thickness. Patients also expressed a significantly greater degree of satisfaction with the treated side as assessed using a subjective 4-point scale. ${ }^{21}$

These previous studies coincide with our results which revealed that fractional $\mathrm{CO}_{2}$ laser could result in improvement in height and pliability. The improvement was highly marked in terms of scar height and pliability and less marked in terms of pigmentation and vascularity, but the overall VSS and each variable showed a significant improvement.

Although the mechanism of fractional photothermolysis in the treatment of atrophic and hypertrophic scar is not known exactly, the columns of thermal injury characterized by localized epidermal necrosis and collagen denaturation may initiate a cascade of events that eventually results in a normalization of the collagenesis-collagenolysis cycle. ${ }^{22}$ Regarding the early fractional $\mathrm{CO}_{2}$ laser intervention, it can, in theory, normalize collagen and realigns abnormal collagen fiber by thermal effect of laser treatment.

\section{Limitations}

There were some limitations in our study, such as being single center in nature, and with variability in initial morphology and, anatomical sites of the scars. Controlled side-to-side comparative studies with larger sample size and longer follow-up period are required. In addition primary outcome measure, although validated, is largely subjective.

\section{Conclusion}

Fractional ablative $\mathrm{CO}_{2}$ laser is an effective and safe treatment modality for surgical scars in the early postsurgical period. Overall improvement was statistically significant in the VSS.

\section{Disclosure}

The authors report no conflicts of interest in this work.

\section{References}

1. Elsaie ML, Choudhary S, Mcleod M, Nouri K. Scars. Curr Probl Dermatol. 2011;42:131.

2. Bian D, Zhang J, Wu X, et al. Asiatic acid isolated from Centella asiatica inhibits TGF- $\beta 1$-induced collagen expression in human keloid fibroblasts via PPAR- $\gamma$ activation. Int J Biol Sci. 2013;9(10):1032-1042.

3. Ibrahim SM, Elsaie ML, Kamel MI, Mohammed EE. Successful treatment of traumatic scars with combined nonablative fractional laser and pinpoint technique of standard $\mathrm{CO}_{2}$ laser. Dermatol Ther. 2016;29(1):52-57. 
4. Lupton JR, Alster TS. Laser scar revision. Dermatol Clin. 2002;20(1): $55-65$.

5. Eilers RE, Ross EV, Cohen JL, Ortiz AE. A combination approach to surgical scars. Dermatol Surg. 2016;42(Suppl 2):S150-S156.

6. Elsaie ML, Choudhary S. Lasers for scars: a review and evidence-based appraisal. J Drugs Dermatol. 2010;9(11):1355-1362.

7. Manuskiatti W, Wanitphakdeedecha R, Fitzpatrick RE. Effect of pulse width of a 595-nm flashlamp-pumped pulsed dye laser on the treatment response of keloidal and hypertrophic sternotomy scars. Dermatol Surg. 2007;33(2):152-161.

8. Choe JH, Park YL, Kim BJ, et al. Prevention of thyroidectomy scar using a new 1,550-nm fractional erbium-glass laser. Dermatol Surg. 2009;35(8):1199-1205.

9. Conologue TD, Norwood C. Treatment of surgical scars with the cryogen-cooled $595 \mathrm{~nm}$ pulsed dye laser starting on the day of suture removal. Dermatol Surg. 2006;32(1):13-20.

10. Yun JS, Choi YJ, Kim WS, Lee GY. Prevention of thyroidectomy scars in Asian adults using a 532-nm potassium titanyl phosphate laser. Dermatol Surg. 2011;37(12):1747-1753.

11. Jung JY, Jeong JJ, Roh HJ, et al. Early postoperative treatment of thyroidectomy scars using a fractional carbon dioxide laser. Dermatol Surg. 2011;37(2):217-223.

12. Oliaei S1, Nelson JS, Fitzpatrick R, Wong BJ. Laser treatment of scars. Facial Plast Surg. 2012;28(5):518-524.

13. Eilers RE, Ross EV, Cohen JL, Ortiz AE. A combination approach to surgical scars. Dermatol Surg. 2016;42(Suppl 2):S150-S156.

14. Nouri K, Jimenez GP, Harrison-Balestra C, Elgart GW. 585-nm pulsed dye laser in the treatment of surgical scars starting on the suture removal day. Dermatol Surg. 2003;29(1):65-73.
15. Tierney E, Mahmoud BH, Srivastava D, Ozog D, Kouba DJ. Treatment of surgical scars with nonablative fractional laser versus pulsed dye laser: a randomized controlled trial. Dermatol Surg. 2009;35(8): $1172-1180$.

16. Kim HS, Kim BJ, Lee JY, Kim HO, Park YM. Effect of the 595-nm pulsed dye laser and ablative 2940-nm Er:YAG fractional laser on fresh surgical scars: an uncontrolled pilot study. J Cosmet Laser Ther. 2011;13(4):176-179.

17. Orringer JS, Rittié L, Baker D, Voorhees JJ, Fisher G. Molecular mechanisms of nonablative fractionated laser resurfacing. Br J Dermatol. 2010;163(4):757-768.

18. Manstein D, Herron GS, Sink RK, Tanner H, Anderson RR. Fractional photothermolysis: a new concept for cutaneous remodeling using microscopic patterns of thermal injury. Lasers Surg Med. 2004;34(5):426-438.

19. Orringer JS, Rittié L, Baker D, Voorhees JJ, Fisher G. Molecular mechanisms of nonablative fractionated laser resurfacing. $\mathrm{Br} J$ Dermatol. 2010;163(4):757-768.

20. Kim HS, Lee JH, Park YM, Lee JY. Comparison of the effectiveness of nonablative fractional laser versus ablative fractional laser in thyroidectomy scar prevention: A pilot study. $J$ Cosmet Laser Ther. 2012;14(2):89-93.

21. Lee SH, Zheng Z, Roh MR. Early postoperative treatment of surgical scars using a fractional carbon dioxide laser: a split-scar, evaluatorblinded study. Dermatol Surg. 2013;39(8):1190-1196.

22. Alster TS, Zaulyanov L. Laser scar revision: a review. Dermatol Surg 2007;33:131-140.
Clinical, Cosmetic and Investigational Dermatology

\section{Publish your work in this journal}

Clinical, Cosmetic and Investigational Dermatology is an international, peer-reviewed, open access, online journal that focuses on the latest clinical and experimental research in all aspects of skin disease and cosmetic interventions. This journal is included on PubMed. The manuscript management system is completely online

\section{Dovepress}

and includes a very quick and fair peer-review system, which is all easy to use. Visit http://www.dovepress.com/testimonials.php to read real quotes from published authors 